\title{
Massa de empada sem glúten: Efeito da combinação de grão de bico e farinha de linhaça nas características nutricionais e sensoriais
}

\author{
Gluten-free pie dough: Effect of the combination of chickpea and flaxseed flour on nutritional and \\ sensory characteristics
}

Masa de tarta sin gluten: Efecto de la combinación de garbanzos y linaza sobre las características nutricionales y sensoriales

Erika Cipriano de Sousa ORCID: https://orcid.org/0000-0003-4426-7754 Universidade do Estado do Rio de Janeiro, Brasil E-mail: erika_15dez@hotmail.com

Heloísa Rodrigues Pessoa ORCID: https://orcid.org/0000-0002-5526-6178 Universidade do Estado do Rio de Janeiro, Brasil E-mail: mrs.pessoa@gmail.com

Karla da Silva Rocha ORCID: https://orcid.org/0000-0001-9242-6487 Universidade do Estado do Rio de Janeiro, Brasil E-mail: karlasilvarocha@gmail.com

Roberta Monteiro Caldeira ORCID: https://orcid.org/0000-0002-1114-9682 Universidade do Estado do Rio de Janeiro, Brasil E-mail: nutricaldeira@gmail.com

Suzana Maria de Lemos Freitas ORCID: https://orcid.org/0000-0002-4906-1328 Universidade do Estado do Rio de Janeiro, Brasil

E-mail: sufreitas9@yahoo.com.br

Renata Rangel Guimarães ORCID: https://orcid.org/0000-0001-6035-9021 Universidade do Estado do Rio de Janeiro, Brasil E-mail: rerangelguimaraes@gmail.com

\begin{abstract}
Resumo
O objetivo do presente estudo foi desenvolver massa de empada à base de grão de bico com adição de farinha de linhaça e avaliar as suas características microbiológicas, sensoriais e nutricionais. Foram desenvolvidas Formulação Padrão (FP), à base de farinha de trigo refinada, e Formulação Experimental (FE), à base de grão de bico e com farinha de linhaça. Foram realizadas análises microbiológica e sensorial e informação nutricional nas massas recheadas assadas. Aplicaram-se testes de aceitação e intenção de compra. FP e FE estavam de acordo com os padrões microbiológicos legais vigentes. Observou-se diferença $(\mathrm{p} \leq 0,05)$ entre FP e FE para todos os atributos; porém, com médias > 7, indicando boa aceitação. Comparada à FP, FE obteve médias menores de textura e sabor, mas bem aceitas, e 52\% dos consumidores comprariam a FE. A FE contém menores teores de gorduras totais e saturadas, sódio e valor energético, e maior de proteínas, comparada à FP, e com 5,6g de fibras alimentares. Grão de bico e farinha de linhaça são viáveis para massa de empada com valores sensorial, nutricional e funcional agregados e potencial de mercado.
\end{abstract}

Palavras-chave: Produto de panificação; Cicer arietinum; Linum usitatissimum; Aceitação.

\begin{abstract}
The aim of the present study was to develop chickpea pie dough with flaxseed flour and to evaluate its microbiological, sensory and nutritional characteristics. Standard Formulation (FP), based on refined wheat flour, and Experimental Formulation (FE), based on chickpeas with flaxseed flour, were developed. Microbiological and sensory analyzes and nutritional information were performed on the stuffed baked pasta. Acceptance and purchase intention tests were applied. FP and FE were in accordance with the current legal microbiological standards. There was a difference $(\mathrm{p} \leq 0.05)$ between FP and FE for all attributes; however, with averages $>7$, indicating good acceptance. Compared to FP, FE obtained lower averages of texture and flavor, but well accepted, and 52\% of consumers would buy FE. The FE contains lower levels of total and saturated fats, sodium and energy value, and higher proteins,
\end{abstract}


compared to FP, and with 5.6g of food fibers. Chickpeas and flaxseed flour are viable for pie dough with added sensory, nutritional and functional values and market potential.

Keywords: Bakery product; Cicer arietinum; Linum usitatissimum; Acceptance.

\section{Resumen}

El objetivo del presente estudio fue desarrollar un masa de tarta sin gluten a base de garbanzos con la adición de harina de linaza y evaluar sus características microbiológicas, sensoriales y nutricionales. Se desarrollaron Formulación Estándar (FP), a base de harina de trigo refinada, y Formulación Experimental (FE), a base de garbanzos y harina de linaza. Se realizaron análisis microbiológicos y sensoriales e información nutricional sobre la masa rellena al horno. Se aplicaron pruebas de aceptación e intención de compra. FP y FE estaban de acuerdo con las normas microbiológicas legales vigentes. Hubo una diferencia $(\mathrm{p} \leq 0.05)$ entre FP y FE para todos los atributos; sin embargo, con promedios $>7$, indicando buena aceptación. Comparado con FP, FE obtuvo promedios más bajos de textura y sabor, pero bien aceptado, y el 52\% de los consumidores compraría FE. EF contiene niveles más bajos de grasas totales y saturadas, sodio y valor energético, y más proteínas, en comparación con FP, y con 5,6 g de fibra dietética. Los garbanzos y la linaza son viables para la masa de tarta con valores sensoriales, nutricionales y funcionales añadidos y potencial de mercado.

Palabras clave: Producto de panadería; Cicer arietinum; Linum usitatissimum; Aceptación.

\section{Introdução}

Farinhas de cereais refinados, amido de milho, batata e tapioca são usualmente utilizados como ingredientes na elaboração de preparações sem glúten, base da alimentação de portadores de doença celíaca (DC). Entretanto, são pobres em fibras alimentares e nutrientes como vitaminas e minerais (Capriles, 2011; Maggio; Orecchio, 2018; Vici, et al., 2016). Neste sentido, torna-se importante buscar alternativas que agreguem valor nutricional aos atributos sensoriais e tecnológicos (Lima, et al., 2017).

Grão de bico e semente de linhaça consistem em alternativas viáveis na fabricação de massas isentas de glúten (Capriles, 2011). O grão de bico (Cicer arietinum) é uma leguminosa que apresenta baixo índice glicêmico (Maurya, et al., 2020), bom teor de carboidratos, minerais e vitaminas (El-Sohaimy, et al., 2020; Kishor, et al., 2017). Essa leguminosa tem um alto teor de fibras alimentares, 12,4 g\%, e um considerável teor proteico, 21,2 g\% (Saget, et al., 2020; Taco 2011; Wallace, et al., 2016).

A semente de linhaça (Linum usitatissimum) é uma excelente fonte de ácidos graxos poli-insaturados da série n-3 e n6, proteínas e fibras alimentares, especialmente as insolúveis (Cupersmid, et al., 2012), sendo um ingrediente viável para o enriquecimento nutricional de produtos alimentícios sem glúten (Monteiro, et al., 2016; Amorim, 2017).

A empada é um salgado popular em quase todos os países do mundo; no entanto, a baixa oferta da versão sem glúten dificulta o seu consumo por indivíduos com intolerância ao glúten e celíacos (Santos, et al., 2017).

A DC é uma enteropatia crônica de caráter autoimune que atinge o intestino delgado, cujo gatilho para o desenvolvimento se dá a partir da exposição ao glúten em indivíduos geneticamente predispostos. Tanto para DC, bem como alergia ao trigo ou para desordens não envolvendo mecanismos alérgicos autoimunes, como a sensibilidade ao glúten não celíaca, o tratamento consiste na exclusão das fontes de glúten da dieta, tais como: trigo, centeio e cevada, variando de acordo com a desordem relacionada ao glúten e às suas manifestações clínicas (Brasil, 2015 a; Brasil, 2015 b; Resende, et al., 2017).

Portadores de DC e intolerantes ao glúten têm dificuldade para encontrar produtos isentos de glúten que apresentem características sensoriais agradáveis e de baixo custo, visto que não são produzidos em larga escala (Santos, et al., 2017). Isso ressalta a necessidade de desenvolvimento e comercialização de novos produtos em mercados regionais e nacionais para este segmento (Lima, et al., 2017).

Nesse contexto, o objetivo do presente estudo foi desenvolver massa de empada à base de grão de bico com adição de farinha de linhaça e avaliar as suas características microbiológicas, sensoriais e nutricionais. 


\section{Metodologia}

\subsection{Matéria-prima}

O estudo foi desenvolvido entre setembro de 2018 e janeiro de 2019 nos laboratórios do Instituto de Nutrição (INU) da Universidade do Estado do Rio de Janeiro (UERJ), campus Maracanã. Todos os ingredientes utilizados foram adquiridos em mercado local do município do Rio de Janeiro.

\subsection{Elaboração das massas de empada}

As concentrações dos ingredientes, bem como a forma de adição do grão de bico, grão ou farinha, e semente de linhaça, inteira ou farinha, foram definidas a partir de testes em um estudo piloto, através das características sensoriais da massa de empada.

Foram desenvolvidas duas formulações de massa de empada: Padrão (FP, à base de farinha de trigo refinada) e Experimental (FE, à base de grão de bico com farinha de linhaça) descritas na Tabela 1.

Tabela 1 - Ingredientes das formulações padrão e experimental.

\begin{tabular}{lcc}
\hline \multicolumn{1}{c}{ Ingredientes da } & \multicolumn{2}{c}{ Formulações } \\
\cline { 2 - 3 } \multicolumn{1}{c}{ Massa (\%) } & FP & FE \\
\hline Farinha de trigo refinada & 60,11 & - \\
Margarina com sal & 37,07 & - \\
Grão de bico cozido & - & 80,10 \\
Farinha de linhaça marrom & - & 9,87 \\
Água filtrada & - & 4,49 \\
Azeite de oliva & - & 3,59 \\
Gema de ovo* & 2,67 & 1,50 \\
Sal refinado & 0,15 & 0,45 \\
\hline
\end{tabular}

FP = Formulação Padrão, à base de farinha de trigo refinada; FE = Formulação Experimental, à base de grão de bico com farinha de linhaça

Recheio para as duas formulações: brócolis refogado com alho, cebola e sal, e requeijão

* Gema de ovo para pincelar a massa

Fonte: Autores.

O fluxograma de elaboração de ambas as formulações de empada, massa e recheio, está descrito na Figura 1. 
Figura 1 - Fluxograma do processo de preparo das formulações padrão e experimental.

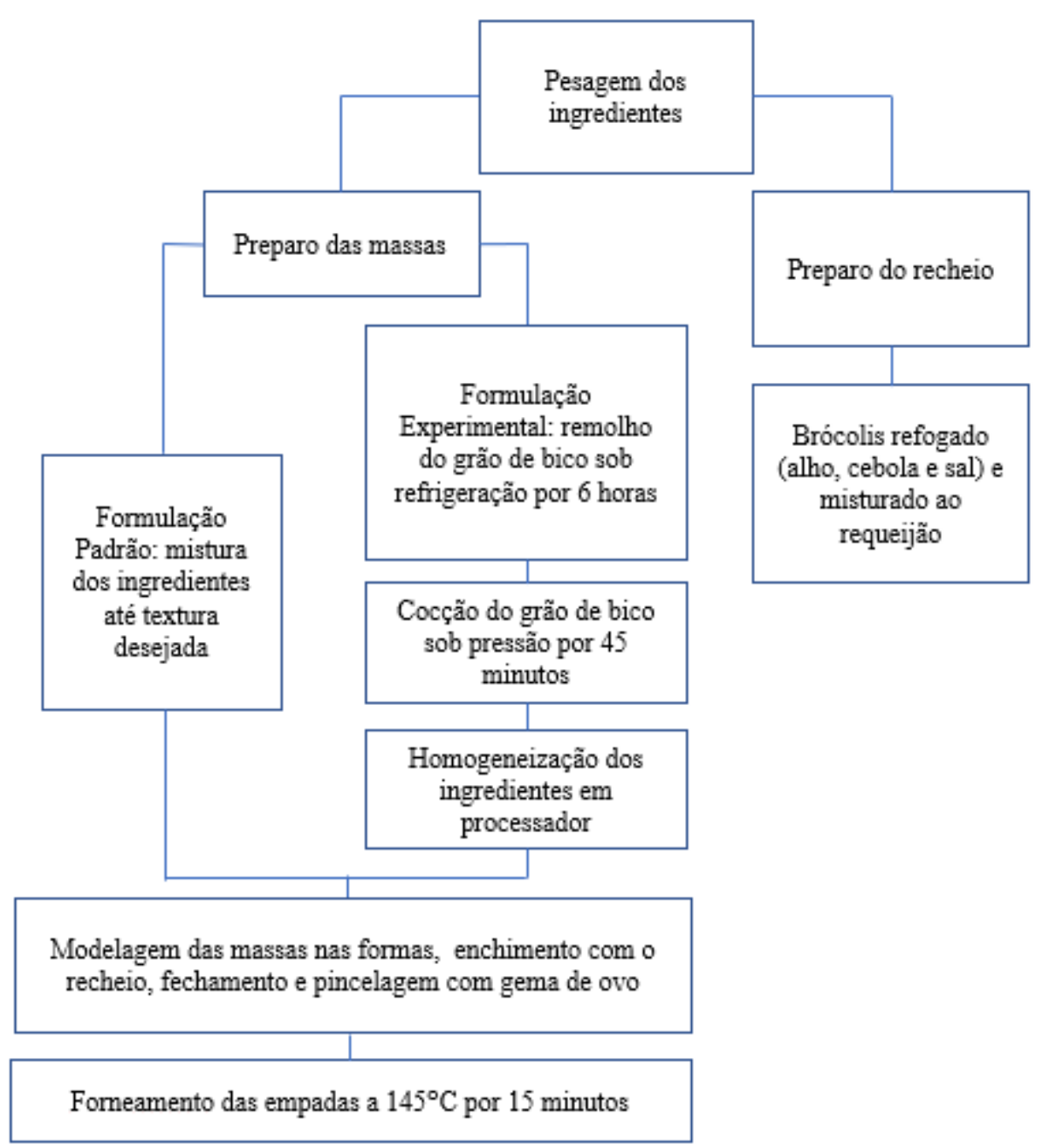

Fonte: Autores.

\subsection{Análise microbiológica}

Para ambas as formulações, foram pesquisados coliformes a $45^{\circ} \mathrm{C} / \mathrm{g}$ por meio da Técnica do Número Mais Provável (NMP/g), Staphylococcus coagulase positiva/g e Bacillus cereus/g pela Técnica da Contagem em Placa por Semeadura em Superfície (UFC/g) e Salmonella sp./25g pelo Método Cultural Clássico de presença/ausência. A metodologia analítica seguiu o protocolo descrito pela American Public Health Association (APHA, 2001) e os resultados comparados à Resolução RDC nº 12, de 02 de janeiro de 2001 (Brasil, 2001), vigente durante o período de ocorrência deste estudo. A avaliação da qualidade microbiológica foi realizada para garantir a inocuidade do produto para a análise sensorial.

\subsection{Análise sensorial}

Foram oferecidas amostras de $30 \mathrm{~g}$ de empada recém-preparadas, e água $(200 \mathrm{~mL})$ para ser ingerida entre as amostras, em blocos incompletos para 50 provadores não treinados, entre estudantes de graduação, pós-graduação, funcionários e visitantes da universidade, os quais aceitaram participar dos testes por livre e espontânea vontade conforme interesse e disponibilidade.

A análise sensorial consistiu na aplicação de teste de aceitação por escala hedônica estruturada de 9 pontos; as notas variavam de 9 (gostei extremamente) a 1 (desgostei extremamente) para os seguintes atributos: aparência, textura, sabor e 
aceitação global. As formulações também foram submetidas a um teste de intenção de compra através de escala de três pontos, onde 1 (certamente compraria), 2 (tenho dúvidas se compraria) e 3 (certamente não compraria).

Foi determinado o Índice de Aceitabilidade (IA) do produto adotando-se a expressão: IA (\%) = (A/B) x 100, na qual A é a nota média obtida para o produto e B é a nota máxima atribuída ao produto. IA $\geq 70 \%$ é considerado como boa aceitação (Dutcosky, 2013).

\subsection{Informação nutricional}

A informação nutricional das formulações de massa de empada foi estimada de acordo com a Tabela Brasileira de Composição de Alimentos (Taco, 2011) e da rotulagem dos produtos utilizados. Foram estimados ainda Valores Diários de Referência (\%VD) e as porções das massas de empada foram calculadas de acordo com a RDC n ${ }^{\circ} 429$, de 08 de outubro de 2020 (Brasil, 2020a).

\subsection{Análise estatística}

Os dados da análise sensorial foram avaliados por meio do teste t de Student com nível de significância de 5\% ( $<<0,05)$, utilizando o software Graph Pad Prism versão 6.0, e expressos como média e desvio-padrão.

\section{Resultados e Discussão}

\subsection{Análise microbiológica}

Os resultados mostraram que não foram detectados coliformes a $45{ }^{\circ} \mathrm{C}$, Salmonella sp., Staphylococcus coagulase positiva e Bacillus cereus. Desta forma, os produtos desenvolvidos estavam de acordo com os padrões microbiológicos legais vigentes (Brasil, 2001) e, portanto, seguros para serem submetidos à avaliação sensorial.

\subsection{Análise sensorial}

Na Tabela 2, estão expressos os resultados do teste de aceitação para os atributos aparência, textura, sabor e aceitação global das formulações padrão e experimental (Figura 2).

Tabela 2 - Teste de aceitação das formulações padrão e experimental.

\begin{tabular}{lcc}
\hline Atributo sensorial & FP & FE \\
\hline Aparência & $8,7 \pm 0,07 \mathrm{a}$ & $6,9 \pm 0,21 \mathrm{~b}$ \\
Textura & $8,6 \pm 0,09 \mathrm{a}$ & $7,7 \pm 0,16 \mathrm{~b}$ \\
Sabor & $8,4 \pm 0,11 \mathrm{a}$ & $7,3 \pm 0,24 \mathrm{~b}$ \\
Aceitação global & $8,4 \pm 0,09 \mathrm{a}$ & $7,2 \pm 0,19 \mathrm{~b}$ \\
\hline
\end{tabular}

FP = Formulação Padrão, à base de farinha de trigo refinada; FE = Formulação Experimental, à base de grão de bico com farinha de linhaça

Recheio para as duas formulações: brócolis refogado com alho, cebola e sal, e requeijão

Valores expressos como média \pm desvio padrão. Letras diferentes na mesma linha, diferem entre si $(\mathrm{p}<0,05)$.

Escala hedônica estruturada de 9 pontos, onde: (1) desgostei extremamente, (2) desgostei muito,

(3) desgostei regularmente, (4) desgostei ligeiramente, (5) nem gostei nem desgostei, (6) gostei ligeiramente,

(7) gostei regularmente, (8) gostei muito e (9) gostei extremamente

Fonte: Autores.

Observou-se diferença estatística $(\mathrm{p}<0,05)$ entre as amostras, FP e FE (Tabela 2), para todos os atributos sensoriais. No entanto, ambas apresentaram médias acima de 7,0 para todos os atributos avaliados. 
Figura 2 - Formulação Padrão (FP) e Formulação Experimental (FE)

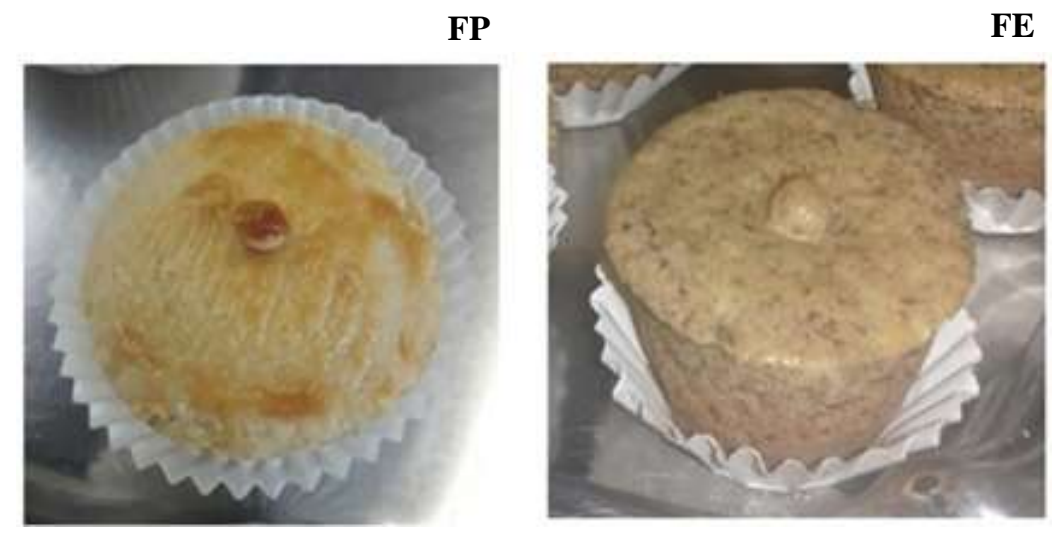

Fonte: Autores.

Outros estudos também investigaram a aceitação sensorial da incorporação do grão de bico a massas panificáveis. Dandachy et al. (2019) ao elaborarem mankoushe zaatar, uma massa libanesa popular feita de farinha de trigo refinada, observaram que a incorporação da farinha de grão de bico na massa, com proporções de 30 e $50 \%$, forneceu produtos com melhores sabor e aceitação global em comparação com o tradicional. Diferente do presente estudo, o qual apesar de a FE ter sido considerada bem aceita nesses atributos, a formulação tradicional obteve notas superiores.

Maurya et al. (2020) afirmaram que existe uma certa dificuldade em se desenvolver massas isentas de glúten, usando o grão de bico como ingrediente, com adequadas textura e firmeza e ainda pelo sabor residual conferido por esta leguminosa. Pasqualone et al. (2019) avaliaram o efeito da adição de farinha de grão de bico preto em produtos de panificação à base de trigo: pão, focaccia e massa de pizza. Tais produtos não obtiveram boa aceitação quanto ao atributo textura. Segundo esses autores, a fraca elasticidade e a redução de expansão de volume das massas podem ser explicadas pela má formação de glúten, devido à ausência dessa proteína na farinha de grão de bico e à riqueza de fibras alimentares. No entanto, no presente estudo este fato não ocorreu. Os resultados mostraram que a utilização do grão de bico na forma de grão cozido promoveu à massa características adequadas de textura e sabor, considerados como boa aceitação pelos provadores ao atribuírem notas 7,7 e 7,3, respectivamente.

Para todos os atributos, o Índice de Aceitabilidade foi superior a 70\%, indicando boa aceitação de ambas as formulações, FP e FE, (Dutcosky, 2013) (Tabela 3). O atributo aceitação global corrobora com o resultado encontrado por Santos et al. (2017), os quais obtiveram um IA igual a 81,2\% para empada sem glúten à base de grão de bico.

Tabela 3 - Índice de Aceitabilidade das formulações padrão e experimental.

\begin{tabular}{lcc}
\hline Índice de Aceitabilidade (\%) & FP & FE \\
\hline Aparência & 96,6 & 76,6 \\
Textura & 95,5 & 85,5 \\
Sabor & 93,3 & 81,1 \\
Aceitação global & 93,3 & 80,0 \\
\hline
\end{tabular}

FP = Formulação Padrão, à base de farinha de trigo refinada; FE = Formulação Experimental, à base de grão de bico com farinha de linhaça

Recheio para as duas formulações: brócolis refogado com alho, cebola e sal, e requeijão

IA $(\%)=(\mathrm{A} / \mathrm{B}) \times 100$, na qual A é a nota média obtida para o produto e B é a nota máxima atribuída ao produto

IA $\geq 70 \%$ é considerado como boa aceitação (Dutcosky, 2013)

Fonte: Autores.

Na Figura 2, estão expressos os resultados do teste de Intenção de Compra das formulações FP e FE. 
Figura 2 - Intenção de Compra da Formulação Padrão (FP) e Formulação Experimental (FE);

FP

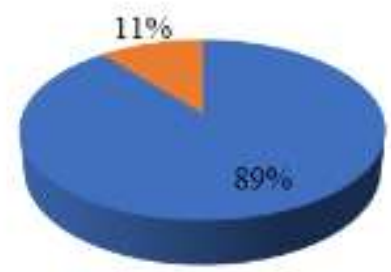

FE

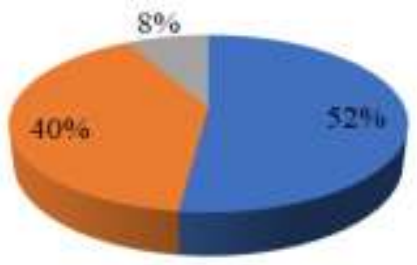

= Certamente compraria

- Tenho dúvidas se compraria

in Certamente nå compraria

Fonte: Autores.

Os resultados indicaram que mais da metade dos consumidores (52\%) certamente comprariam a FE.

\subsection{Informação nutricional}

A Figura 3 apresenta as informações nutricionais das formulações FP e FE.

Figura 3 - Informação nutricional das massas de empada FP e FE.

\begin{tabular}{|c|c|c|c|c|c|c|}
\hline \multicolumn{7}{|c|}{ INFORMAÇÃO NUTRICIONAL } \\
\hline & \multicolumn{3}{|c|}{ FP } & \multicolumn{3}{|c|}{ FE } \\
\hline & $100 \mathrm{~g}$ & $\begin{array}{l}\text { Porção } 37 g \\
\text { (1 unidade) }\end{array}$ & $\begin{array}{c}\% \\
\text { VDR } \\
(*) \\
\end{array}$ & $100 \mathrm{~g}$ & $\begin{array}{l}\text { Porção } 81 \text { g } \\
\text { (1 unidade) }\end{array}$ & $\begin{array}{c}\% \\
\text { VDR } \\
(*) \\
\end{array}$ \\
\hline Valor energético & $405 \mathrm{kcal}$ & $150 \mathrm{kcal}$ & 8 & $185 \mathrm{kcal}$ & $150 \mathrm{kcal}$ & 8 \\
\hline Carboidratos & $40 \mathrm{~g}$ & $15 \mathrm{~g}$ & 5 & $11,6 \mathrm{~g}$ & $9,4 \mathrm{~g}$ & 3,9 \\
\hline Proteínas & $6,5 \mathrm{~g}$ & $2,4 \mathrm{~g}$ & 4,8 & $3,7 \mathrm{~g}$ & $3,0 \mathrm{~g}$ & 6 \\
\hline Gorduras totais & $24 \mathrm{~g}$ & $9,0 \mathrm{~g}$ & 14 & $7,5 \mathrm{~g}$ & $6,1 \mathrm{~g}$ & 9,4 \\
\hline Gorduras saturadas & $6,2 \mathrm{~g}$ & $2,3 \mathrm{~g}$ & 12 & $2,5 \mathrm{~g}$ & $2,0 \mathrm{~g}$ & 10 \\
\hline Gorduras trans & $3,2 \mathrm{~g}$ & $1,2 \mathrm{~g}$ & 60 & $\begin{array}{c}\text { não } \\
\text { contém }\end{array}$ & $\begin{array}{c}\text { não } \\
\text { contém }\end{array}$ & $* *$ \\
\hline Fibra alimentar & $1,6 \mathrm{~g}$ & $0,6 \mathrm{~g}$ & 2,4 & $6,9 \mathrm{~g}$ & $5,6 \mathrm{~g}$ & 22 \\
\hline Sódio & $370 \mathrm{mg}$ & $137 \mathrm{mg}$ & 6,8 & $160 \mathrm{mg}$ & $130 \mathrm{mg}$ & 6,5 \\
\hline $\begin{array}{l}\text { *\% Valores Diários d } \\
\text { diários podem ser m } \\
\text { estabelecido. }\end{array}$ & $\begin{array}{l}\text { Referência } \\
\text { ores ou n }\end{array}$ & $\begin{array}{l}\text { necido pela por } \\
\text { ores dependen }\end{array}$ & $\begin{array}{l}\mathrm{om} \mathrm{b} \\
\mathrm{e} \mathrm{su}\end{array}$ & $\begin{array}{l}\text { em uma } \\
\text { necessida }\end{array}$ & $\begin{array}{l}\text { de } 2.000 \mathrm{kcal} \text {. } \\
\text { energéticas. }\end{array}$ & $\begin{array}{l}\text { s valores } \\
\text { DR não }\end{array}$ \\
\hline
\end{tabular}

As porções das formulações são diferentes, uma vez que foram calculadas com base no valor energético ideal à porção (150 kcal/porção), de acordo com a legislação vigente (Brasil, 2020b). A porção de $81 \mathrm{~g}$ da FE contém menores quantidades de gorduras totais, gorduras saturadas, sódio e valor energético, e maior teor de proteínas, comparada à porção de $37 \mathrm{~g}$ da FP.

De acordo com Lima et al. (2017), usualmente aos alimentos sem glúten são acrescidas gorduras para melhorar as suas características tecnológicas. No entanto, esses autores encontraram menores teores de lipídeos em massa alimentícia à base de farinha de grão de bico em relação à massa alimentícia tradicional, de farinha de trigo. No presente estudo, a adição do 
grão de bico como ingrediente para as massas permitiu a redução de gorduras, além de ter sido uma alternativa viável para aumentar o teor de proteínas.

A adição de grão de bico e farinha de linhaça contribuíram para aumentar o teor de fibras alimentares da FE, a qual apresentou 5,6 g de fibras alimentares na porção e, portanto, pode ser considerada como "alto conteúdo", visto que segundo a Instrução Normativa-IN n 75, de 08 de outubro de 2020 (Brasil, 2020b), para se enquadrar nesta categoria, uma porção deve ter no mínimo 20\% dos Valores Diários de Referência.

No estudo descrito por Santos et al. (2017), foi elaborada uma empada sem glúten com massa à base de grão de bico e recheio de frango e pupunha. Foi considerada como alto conteúdo de fibras alimentares, visto que contém $8 \mathrm{~g}$ de fibra alimentar em $100 \mathrm{~g}$ de empada com recheio e como fonte de proteínas por conter $20 \mathrm{~g}$ de proteínas em $100 \mathrm{~g}$ de empada, diferente do presente estudo que encontrou 3,7\% de proteínas e 6,9\% de fibras alimentares na massa experimental, sem incluir o recheio. A massa de empada experimental obteve quantidade de proteína maior e valor energético menor quando comparada à massa tradicional. Este maior teor proteico associado a um menor valor energético proporciona melhor qualidade nutricional da $\mathrm{FE}$ em relação à FP, destacando-se que a FE por não conter glúten, também favorece os portadores de DC e intolerantes ao glúten.

Neste contexto, busca-se cada vez mais a utilização de farinhas livres de glúten, ricas em fibras alimentares e proteínas, como ingredientes na elaboração de produtos sem glúten, a fim de agregar valor funcional e melhorar o seu perfil nutricional, em detrimento ao uso de amidos e farinhas refinados (Padalino, 2016; Vici, et al., 2016).

\section{Considerações Finais}

Grão de bico e farinha de linhaça são ingredientes viáveis para o desenvolvimento de massa de empada com boa aceitação, características sensoriais adequadas, melhora do perfil nutricional, valor funcional agregado e potencial de mercado. Neste sentido, oportuniza a oferta no comércio de produtos hipoalergênicos isentos de glúten com propriedades salutares para indivíduos com restrição ao consumo desta proteína.

Vale ressaltar que é importante ainda a realização de novos estudos que desenvolvam produtos alimentícios com alegação para fins especiais voltada para os portadores de doença celíaca e de intolerância e alergias alimentares, bem como de pesquisas sobre políticas públicas de incentivo à inclusão desses produtos no mercado.

\section{Agradecimentos}

Agradecemos ao Instituto de Nutrição (INU) da Universidade do Estado do Rio de Janeiro (UERJ) e à equipe de professores e técnicos do Estágio Supervisionado em Segurança e Ciências de Alimentos (INU/UERJ).

\section{Referências}

Amorim, E. G. (2017). Benefícios da utilização de linhaça na formulação de novos produtos epreparações. Arquivos Brasileiros de Alimentação, 2(3), 210222.

APHA. American Public Health Association. (2001). Compendium of methods for the microbiological examination of foods. APHA.

Brasil. (2001). Resolução RDC $n^{o}$ 12, de 2 de janeiro de 2001. http://portal.anvisa.gov.br/documents/33880/2568070/RDC_12_2001.pdf/15ffddf6-3767-4527bfac-740a0400829b.

Brasil. (2015). Portaria $n^{o} 1149$, de 11 de novembro de 2015. http://bvsms.saude.gov.br/bvs/saudelegis/sas/2015/prt1149_11_11_2015.html.

Brasil. (2020a). Resolução RDC n $n^{\circ} 429$, de 8 de outubro de 2020. http://antigo.anvisa.gov.br/documents/10181/3882585/RDC_429_2020_.pdf/9dc15f3a-db4c4d3f-90d8-ef4b80537380.

Brasil. (2020b). Instrução Normativa-IN no 75, de 8 de outubro de 2020. http://antigo.anvisa.gov.br/documents/10181/3882585/IN+75_2020_.pdf/7d74fe2de187-4136-9fa2-36a8dcfc0f8f. 
Research, Society and Development, v. 10, n. 8, e11010816971, 2021

(CC BY 4.0) | ISSN 2525-3409 | DOI: http://dx.doi.org/10.33448/rsd-v10i8.16971

Brasil, T. A., Capitani, C. D., Takeuchi, K. P. \& Ferreira, T. A. P. de C. (2015). Physical, chemical and sensory properties of gluten-free kibbeh formulated with milletflour (Pennisetum glaucum (L.) R. Br.). Food Science and Technology, 35(2), 361-367.

Capriles, V. D. \& Arêas, J. A. G. (2011). Avanços na produção de pães sem glúten: aspectos tecnológicos e nutricionais. Boletim do Centro de Pesquisa de Processamento de Alimentos, 29(1), 129-136.

Cupersmid, L., Fraga, A. P. R., Abreu, E. S. de \& Pereira, I. R. O. (2012). Linhaça: composição química e efeitos biológicos. Scientia, 5(2), 33-40.

Dandachy, S., Mawlawi, H. \& Obeid, O. (2019). Effect of Processed Chickpea Flour Incorporation on Sensory Properties of Mankoushe Zaatar. Foods, 8(5), 151.

Dutcosky, S. D. (2013). Análise sensorial de alimentos. Champagnat.

Kishor, K., David, J., Tiwari, S., Singh, A. \& Rai, B. S. (2017). Nutricional composition of Chickpea (Cicer arietinum) Milk. Internation Journal of Chemical Studies, 5(4), 1941-1944.

El-Sohaimy, S. A., Brennan, M., Darwish, A. M. G. \& Brennan, C. (2020). Physicochemical, texture and sensorial evaluation of pasta enriched with chickpea flour and protein isolate. Annals of Agricultural Sciences, 65, 28-34.

Lima, B. R., Botelho, R. B. A. \& Zandonadi, R. P. (2019). Gluten-free pasta: replacing wheat with chickpea. Journal of culinary Science \& technology, $17(1), 1-8$.

Maggio, A. \& Orecchio, S. (2018). Fatty acid composition of gluten-free food (bakery products) for celiac people. Foods, 7(6), 95.

Maurya, S., Malani, J. \& Avhad, P. (2020). Development of gluten-free chickpea and white pea flour pasta with addition of pre-gelatinized starch. Research Gate. https://www.researchgate.net/publication/341542846.

Monteiro, W. L. A., Rosa, G., Luiz, R. R., Neto, J. F. N. \& Oliveira, G. M. M. de (2016). Efeitos de diferentes tipos de linhaça nas sensações de apetite e saciedade no sobrepeso e na obesidade. International Journal of Cardiovascular Sciences. 29(1), 37-46.

Padalino, L., Conte, A., Del Nobile, M. A. (2016). Overview on the general approaches to improve gluten-free pasta and bread. Foods, $4(5), 87$.

Pasqualone, A., Angelis, D. De, Squeo, G., Difonzo, G., Caponio, F. \& Summo, C. (2019). The Effect of the Addition of Apulian black Chickpea Flour on the Nutritional and Qualitative Properties of Durum Wheat-Based Bakery Products. Foods, 8, 504.

Resende, P. V. G., Silva, N. L. M., Schettino, G. C. M. \& Liu, P. M. F. (2017). Doenças relacionadas ao glúten. Revista de Medicina, 27 (Supl 3), S51-S58.

Santos, I. H. V. da S., Souza, I. C. de F., Silva, S. C. B. da, Nascimento, K. P. da S. M., Oliveira, T. W. de, Lima, E. M. C. \& Souza, S. F. N. de (2017). Análise nutricional e de aceitabilidade de empada à base de grão-de-bico, com recheio de frango com pupunha. Revista Saber Científico, 6(2), $26-34$.

Taco. (2011). Tabela brasileira de composição de alimentos. NEPA-UNICAMP.

Vici, G., Belli, L., Biondi, M., Polzonetti, V. (2016). Gluten free diet and nutrient deficiencies: a review. Clinical Nutrition, 35(6), 1236-1241.

Wallace, T., Murray, R., Zelman, K. M. (2016). The Nutritional Value and Health Benefits of Chickpeas and Hummus. Nutrients, 8(12), 766. 